\title{
Salsolinol modulation of dopamine neurons
}

\author{
Guiqin Xie ${ }^{1,2}$, Krešimir Krnjević ${ }^{3}$ and Jiang-Hong Ye ${ }^{1 *}$ \\ Department of Anesthesiology, Pharmacology, and Physiology, New Jersey Medical School, University of Medicine and Dentistry of New Jersey, Newark, \\ NJ, USA \\ 2 Department of Physiology, Nanjing Medical University, Nanjing, China \\ ${ }^{3}$ Department of Physiology, McGill University, Montreal, OC, Canada
}

Edited by:

Merce Correa, University Jaume I,

Spain

Reviewed by:

Mark S. Brodie, University of Illinois

at Chicago, USA

Luis Granero, Universitat de

Valencia, Spain

*Correspondence:

Jiang-Hong Ye, Department of

Anesthesiology, Pharmacology, and

Physiology, New Jersey Medical

School, University of Medicine and

Dentistry of New Jersey, Newark,

NJ 07103, USA.

e-mail: ye@umdnj.edu
Salsolinol, a tetrahydroisoquinoline present in the human and rat brains, is the condensation product of dopamine and acetaldehyde, the first metabolite of ethanol. Previous evidence obtained in vivo links salsolinol with the mesolimbic dopaminergic (DA) system: salsolinol is self-administered into the posterior of the ventral tegmental area (pVTA) of rats; intra-VTA administration of salsolinol induces a strong conditional place preference and increases dopamine release in the nucleus accumbens (NAc). However, the underlying neuronal mechanisms are unclear. Here we present an overview of some of the recent research on this topic. Electrophysiological studies reveal that DA neurons in the pVTA are a target of salsolinol. In acute brain slices from rats, salsolinol increases the excitability and accelerates the ongoing firing of dopamine neurons in the PVTA. Intriguingly, this action of salsolinol involves multiple pre- and post-synaptic mechanisms, including: (1) depolarizing dopamine neurons; (2) by activating $\mu$ opioid receptors on the GABAergic inputs to dopamine neurons - which decreases GABAergic activity - dopamine neurons are disinhibited; and (3) enhancing presynaptic glutamatergic transmission onto dopamine neurons via activation of dopamine type 1 receptors, probably situated on the glutamatergic terminals. These novel mechanisms may contribute to the rewarding/reinforcing properties of salsolinol observed in vivo.

Keywords: reward, addictive property, electrophysiology, brain slices, mu opioid receptors, GABAergic transmission, glutamatergic transmissions, dopaminergic neurons

\section{INTRODUCTION}

Alcohol/Ethanol is one of the most widely used drugs and the global burden of alcoholism is immense, with an estimated 3.8\% (Rehm et al., 2009) or 3.2\% (Spanagel et al., 2010) of worldwide deaths attributed to alcohol consumption. Accumulating evidence suggests that some addictive properties of alcohol are generated by its metabolites, such as acetaldehyde and its derivatives, notably salsolinol (SAL, 1-methyl-1,2,3,4-tetrahydro6,7-dihydroxy-isoquinolines) (Deng and Deitrich, 2008). SAL is formed from dopamine: either by non-enzymatic Pictet-Spengler condensation with acetaldehyde, yielding racemic (R/S)-SAL, or by combination with pyruvic acid, followed by enzymatic decarboxylation and reduction, producing (R)-SAL. In the brains of mammals racemic (R/S)-SAL is formed by the Pictet-Spengler condensation (Rommelspacher et al., 1995; Haber et al., 1996). In the human brain, enantio-selective (R)-SAL can be synthesized from dopamine and acetaldehyde by (R)-SAL synthase (Naoi et al., 1998). (R/S)-SAL is present in biological fluids such as urine, plasma, cerebrospinal fluid and postmortem brains of both alcoholics and non-alcoholics (Sjöquist et al., 1982b; Haber et al., 1996). The effects of alcohol consumption on SAL concentrations in the biological fluids and the brain have been extensively reviewed by Hipolito et al. (2012).

Many studies have attempted to establish a correlation between alcohol ingestion and the increase of SAL levels in brain tissues. According to the majority, chronic alcohol exposure produces an increase in SAL levels in several brain regions such as the striatum, hypothalamus and limbic regions (Sjöquist et al., 1982a,b; Myers et al., 1985; Matsubara et al., 1987; Rojkovicova et al., 2008). The increase varied remarkably ranging from 0.08 (Starkey et al., 2006) to $7.59 \mathrm{pg} / \mathrm{mg}$ (Rojkovicova et al., 2008). With one exception (Haber et al., 1996), previous human studies found that, after acute (Faraj et al., 1989; Rommelspacher et al., 1995) or chronic (Faraj et al., 1989) alcohol drinking, SAL levels rise in plasma (and presumably brain). Recent evidence that SAL in the brain accounts for some aspects of alcohol's addictive properties have been elegantly reviewed (Hipolito et al., 2012; Deehan et al., 2013a,b); but still little is known about how SAL acts at the cellular level.

The midbrain ventral tegmental area (VTA) has been extensively studied as a target for the central effects of alcohol (Morikawa and Morrisett, 2010), its first metabolite acetaldehyde (Melis et al., 2009; Karahanian et al., 2011), as well as its metabolic derivative SAL (Hipolito et al., 2012). The majority of neurons in the VTA are either dopaminergic (DA) or GABAergic (Lacey et al., 1989; Yung et al., 1991; Johnson and North, 1992b; Chieng et al., 2011), with only a few glutamatergic neurons (Nair-Roberts et al., 2008). The VTA DA neurons project mainly to the nucleus accumbens (NAc) and prefrontal cortex (PFC) (Oades and Halliday, 1987). Dopamine is involved in self-administration of most drugs of abuse, and drugs abused by humans increase dopamine output in target regions of the brain (Di Chiara and Imperato, 1988; Volkow et al., 2007). Addictive substances of different types modulate 
DA neuron activity and dopamine release from the VTA (Lüscher and Malenka, 2011). Recently, we employed patch clamp in combination with pharmacological techniques to investigate SAL's immediate effects on VTA DA neurons in rat brain slices (Xie and Ye, 2012; Xie et al., 2012). We found that SAL (0.01-1 $\mu \mathrm{M})$ significantly stimulates the activity of DA neurons. In this review, we will focus on the multiple underlying cellular mechanisms, in order to clarify how SAL modulates neuronal excitability in the VTA.

\section{SAL's PSYCHOACTIVE EFFECTS IN THE MESOLIMBIC DOPAMINE SYSTEM In vivo}

Research from several laboratories has led to the idea that SAL participates in ethanol's psychoactive effects in rodents through its own rewarding properties. Early animal studies revealed that SAL promotes alcohol drinking (Duncan and Deitrich, 1980; Myers et al., 1982). Recent data from several groups support the notion that SAL is responsible for some addiction-related psychoactive behaviors related to the mesolimbic dopamine system. Indeed, in Wistar rats, microinjections of SAL $(5,25 \mu \mathrm{M})$ into the NAc core increase local dopamine extracellular levels (measured by HPLC), whereas the same doses of SAL injected into the NAc shell significantly reduced the dopamine levels in that subregion (Hipolito et al., 2009). However, microinjection of SAL into the posterior VTA increased DA levels in the ipsilateral accumbens shell by 41\% (Hipolito et al., 2009). Recently, Deehan et al. (2013a,b) also reported that SAL stimulates dopamine release in the posterior ventral tegmental area (pVTA). In this study, the effects of SAL on dopamine release were dose-dependent, in an inverted U-shape manner, with $0.3 \mu \mathrm{M}$ SAL producing a peak dopamine efflux (to 300\% of baseline) and higher concentrations $(3 \mu \mathrm{M})$ a significantly lower response (Deehan et al., 2013a,b). In parallel with these neurochemical findings, SAL elicited some behavioral effects. Direct injection of only 30 pmol SAL into the pVTA resulted in behavioral sensitization and induced strong motor activity in rats (Hipolito et al., 2010). Moreover, significant place preference was induced by SAL, given either intraperitoneally (ip) (Matsuzawa et al., 2000) or by local microinjection into the pVTA (Hipolito et al., 2011). Rodd and colleagues found that rats readily self-administered SAL into the NAc shell (Rodd et al., 2003, 2008) and pVTA (Rodd et al., 2008). Such reinforcing actions seem to depend on activation of DA neurons, being reduced by co-infusion of quinpirole [a D $(2,3)$ receptor agonist] (Rodd et al., 2008). Below, we will discuss the possible cellular mechanisms underlying these psychoactive effects of SAL, in the light of our recent findings in brain slices in vitro.

\section{SAL DEPOLARIZES pVTA DA NEURONS In vitro AND ACCELERATES THEIR DISCHARGE}

Under current-clamp, SAL was found to depolarize the membrane potential of VTA DA neurons in rats (Xie et al., 2012). In keeping with this depolarization, SAL increased the firing rate of DA neurons in a reversible and dose-dependent manner, with a peak effect at $0.1 \mu \mathrm{M}$. This dose dependence, however, was biphasic: at concentrations of $0.01-0.1 \mu \mathrm{M}$, the firing rate increased with SAL concentration; but at higher concentrations, the increase diminished sharply. Such concentrations are within a pharmacologically relevant range (Matsubara et al., 1987; Haber et al., 1999). This inverted, U-shaped concentration response curve seen in vitro is remarkably similar to the concentration dependence of SAL intra-pVTA microinjections effect on locomotor activity: this dose-response curve had an inverted U-shaped profile, with a peak at 30 pmol (Hipolito et al., 2010). Rodd et al. found that $0.03-0.3 \mu \mathrm{M}$ SAL was readily self-administered when injected directly into the posterior, not anterior VTA of Wistar rats (Rodd et al., 2008). Notably, our in vitro and those in vivo experiments revealed that SAL is far more potent than ethanol as stimulator of DA neurons in the pVTA. In contrast to the strong activation induced by $0.1 \mu \mathrm{M}$ SAL, ethanol had a similar effect only at concentrations of 100 200 mM (Brodie et al., 1990; Xiao et al., 2007). Thus, SAL is 1-2 million times more effective than ethanol as stimulator of DA neurons in the pVTA.

\section{GABAergic AND GLUTAMATERGIC TRANSMISSIONS IN THE VTA PLAY A CRITICAL ROLE IN SAL's EFFECT DISINHIBITION THROUGH THE ACTIVATION OF $\mu$ OPIOID RECEPTORS (MORs) ON GABAergic AFFERENTS}

The projection neurons in the VTA, mostly DA neurons, are under inhibitory GABAergic control. Several GABAergic inputs are known, including those from GABA neurons in the rostomedial tegmental nucleus (RMTg) (Barrot et al., 2012), local GABA neurons (i.e., interneurons) (Johnson and North, 1992a; Lüscher and Malenka, 2011; Omelchenko et al., 2009; Tan et al., 2012), medium spiny neurons of the NAc and the ventral pallidum (Kalivas, 1993; Kalivas et al., 1993; Hjelmstad et al., 2013). Both $\mathrm{GABA}_{\mathrm{A}}$ and $\mathrm{GABA}_{\mathrm{B}}$ receptors mediate the inhibitory action of GABA on DA neurons (Johnson and North, 1992a; Brazhnik et al., 2008; Theile et al., 2011). Both in vivo and in vitro, blockade of GABA $_{\mathrm{A}}$ Rs strongly increases DA cell firing (Johnson and North, 1992a; Xiao et al., 2007; Matsui and Williams, 2011; Theile et al., 2011; Guan et al., 2012); GABAergic IPSCs therefore normally dampen the excitability of DA neurons. GABA $\mathrm{R}$ blockade in the VTA increases dopamine levels in the NAc (Ikemoto et al., 1997) and is strongly rewarding (Laviolette and van der Kooy, 2001). Several lines of evidence have linked ethanol-induced reinforcement to the GABAergic system in the VTA. For example, VTA GABA neurons become hyperexcitable during ethanol withdrawal (Gallegos et al., 1999). Both systemic and intra-VTA administration of $\mathrm{GABA}_{\mathrm{A}} \mathrm{R}$ agonists facilitate, whereas antagonists decrease, voluntary ethanol drinking in rats (Smith et al., 1992). In line with these in vivo studies, we have recently reported several relevant findings obtained in vitro, during recordings of neuronal activity in brain slices from rats (Xiao et al., 2007; Xiao and Ye, 2008). Thus, ethanol inhibited GABA neurons (through activation of MORs); it enhanced DA neuron firing. Moreover, $\mathrm{GABA}_{\mathrm{A}}$ antagonists such as bicuculline and gabazine, attenuate the ethanol-induced increase in firing of VTA-DA neurons. Further tests revealed an involvement of $\mu$ opioid receptors (MORs) as the MOR agonist DAMGO and MOR antagonist naltrexone significantly attenuated the increase in firing induced by ethanol and even altered the basal firing rate of the DA neurons, indicating ongoing opioid modulation (Xiao et al., 2007; 
Xiao and Ye, 2008). By contrast, Theile (Theile et al., 2011) reported that while ethanol-acceleration of the firing rate of VTA DA neurons was increased by picrotoxin, an antagonist of $\mathrm{GABA}_{\mathrm{A}}$ and glycine receptors, it was unaffected by naltrexone, and DAMGO did not change the ongoing firing. This apparent difference suggests some links between MORs, GABA $\mathrm{Rs}$ and the effect of ethanol on DA neurons.

Compared to the role of GABA in ethanol abuse, we know much less about how SAL affects GABAergic transmission. Previous studies have found that SAL is a morphine-like alkaloid. It binds to opioid receptors and has opioid-like effects (Fertel et al., 1980; Lucchi et al., 1982). We found (Xie et al., 2012) that both gabazine and naltrexone reduce the acceleration of DA neuronal firing produced by SAL, suggesting that SAL's action may be mediated via MOR on GABAergic neurons. In support of this idea, SAL reduced the frequency of spontaneous IPSCs recorded in DA neurons, without changing their amplitude; but SAL decreased the size of evoked IPSCs and increased the paired-pulse ratio. These observations indicate that SAL depresses GABAergic transmission to DA neurons by an opioid sensitive presynaptic mechanism. Indeed, SAL's effect on sIPSCs was suppressed by naltrexone or DAMGO. MORs are enriched in the VTA and are primarily located on non-DA neurons (Mansour et al., 1995), the RMTg and its efferents to the DA neurons (Jhou et al., 2009; Jalabert et al., 2011; Matsui and Williams, 2011; Hjelmstad et al., 2013). It is generally believed that MORs-mediated inhibition of GABAergic neurons leads to excitation of DA neurons by a disinhibitory mechanism (Johnson and North, 1992a; Jalabert et al., 2011; Matsui and Williams, 2011). In keeping with this idea, both systemic and intra-VTA administrations of MOR agonists increase VTA DA neuron firing and NAc dopamine release (Matthews and German, 1984; Latimer et al., 1987; Di Chiara and Imperato, 1988; Leone et al., 1991; Spanagel et al., 1992). Previous experiments in vivo have shown that SAL-associated place preference was blocked by intraperitoneal or local administration of $\beta$-Funaltrexamine, an antagonist of MORs (Matsuzawa et al., 2000). Local pretreatment with $\beta$-Funaltrexamine hydrochloride also prevented the SAL-evoked increase in NAc dopamine levels (Hipolito et al., 2011). Our observation of pronounced effects of naltrexone on GABAergic IPSCs is strong evidence of ongoing opioid release in the VTA (Xiao et al., 2007; Xiao and Ye, 2008; Xie et al., 2012). Moreover, naltrexone largely eliminated the effects of SAL on DA neurons. The simplest explanation of our results is that SAL activates MORs on GABAergic neurons or their efferents, thus exciting VTA DA neurons by disinhibition. Overall, our in vitro findings are consistent with the notion that SAL's excitatory effects in rat pVTA are mediated, at least partly, by activation of MORs (Hipolito et al., 2011) and the resulting suppression of GABAergic inhibition. How SAL activates MORs remains to be clarified. Though known to bind to opioid receptors, it has only a low affinity, significant binding requiring relatively high micromolar concentrations of SAL (Fertel et al., 1980; Lucchi et al., 1982). The binding of SAL lowers the binding of endogenous opioids. Therefore, other mechanisms of SAL action at very low concentrations, such as enhanced release or slower removal of endogenous opioid, should also be considered.

\section{GLUTAMATERGIC TRANSMISSION TO VTA IS ENHANCED BY SAL-INDUCED ACTIVATION OF D1Rs}

VTA DA neurons receive numerous glutamatergic afferents from many parts of the brain, including the PFC (Sesack et al., 2003; Geisler et al., 2007) and subcortical structures, such as the pedunculopontine (PPTg) and laterodorsal tegmental (LDTg) nuclei (Charara et al., 1996; Clements et al., 1991; Lavoie and Parent, 1994), the bed nucleus of the stria terminals (BNST) (Georges and Aston-Jones, 2002), the superior colliculus (SC) (Comoli et al., 2003; Dommett et al., 2005), the lateral hypothalamic and preoptic areas, periaqueductal gray, the dorsal and median raphe (Geisler et al., 2007), as well as the lateral habenula (Gonçalves et al., 2012). Some glutamatergic neurons are also present within the VTA (Dobi et al., 2010). Excitatory synaptic inputs which activate $\alpha$-amino-3-hydroxy-5-methyl-4-isoxazolepropionic acid (AMPA), and NMDA-type ionotropic glutamate receptors in DA neurons are a key component in the regulation of DA cell excitability (Overton and Clark, 1997). Accordingly, iontophoretic applications of both AMPA and NMDA receptor agonists can stimulate DA neuron firing (Christoffersen and Meltzer, 1995; Zhang et al., 1997). Consistently, applications of APV + DNQX (AMPA and NMDA receptor antagonists, respectively) slightly but significantly lower the firing rate of DA neurons (Xie and Ye, 2012).

Glutamatergic transmission plays an important role in the effects of ethanol (Eckardt et al., 1998; Krystal et al., 2003). In several brain regions, ethanol inhibits NMDA and nonNMDA glutamate receptors, as well as glutamate release (Siggins et al., 2005). However, ethanol can increase glutamate release under some circumstances. Systemic administration of ethanol increases glutamate release in the NAc of low-alcohol sensitive rats (Dahchour et al., 2000) and addiction-prone Lewis rats (Selim and Bradberry, 1996). Acute ethanol administration increases glutamate release in the central nucleus of the amygdala from rats receiving chronic ethanol treatment (Roberto et al., 2004; Zhu et al., 2007). Both acute and repeated exposure to low doses of ethanol raised glutamate levels in the pVTA (Ding et al., 2012). We have previously reported that ethanol enhances glutamatergic transmission to VTA DA neurons (Deng et al., 2009; Xiao et al., 2009). Most recently, we found that SAL also enhances glutamatergic transmission to DA neurons in the VTA, increasing the frequency of both firing and spontaneous EPSCs (Xie and Ye, 2012). The application of APV + DNQX substantially attenuated SAL's action on firing, indicating a very substantial glutamatergic component in SALinduced excitation of DA neurons. The increase in frequency of spontaneous EPSCs was abolished by the sodium channel blocker tetrodotoxin, indicating that SAL's effect involved voltagedependent $\mathrm{Na}^{+}$channels. Since SAL did not alter the amplitude of either sEPSCs or mEPSCs, but increased the $\mathrm{EPSC}_{2} / \mathrm{EPSC}_{1}$ ratio during paired-pulse stimulation, its site of action was probably presynaptic. These findings clearly point to the involvement of glutamatergic transmission in SAL's effects in VTA. Dopamine receptors consist of D1-like (D1 and D5 receptors) and D2like (D2, D3, and D4 receptors) families. Both D1R and the D2R family (D2R in particular) have been implicated in the mechanisms of drug dependence and abuse (Blum et al., 1990). 
Disruption of D1R gene expression (El-Ghundi et al., 1998) or administration of a D1R antagonist (Liu and Weiss, 2002) attenuates or prevents alcohol-seeking behavior. In the VTA, D1Rs are expressed on glutamatergic axons (Lu et al., 1997) but not on the soma of VTA DA neurons (Mansour et al., 1992; Lu et al., 1997). The activation of D1Rs increases glutamate levels in the VTA (Kalivas and Duffy, 1995). In our experiments, SKF83566 (a selective D1R antagonist), suppressed SAL's action on evoked EPSCs in VTA, confirming that the enhancement of glutamatergic transmission was mediated by D1Rs. We also found that SKF83566 attenuated the SAL-induced acceleration of DA neuron firing. SAL may thus increase the somatodendritic release of dopamine; and by raising the extracellular level of dopamine may retrogradely activate the D1Rs on the glutamate-releasing terminals, which in turn increases glutamate release and the excitability of DA neurons. Somatodendritic release of dopamine in the midbrain DA neurons is $\mathrm{Na}^{+}$channel-dependent (Threlfell and Cragg, 2007). In keeping with this, we found that the increase in the frequency of spontaneous EPSCs by SAL was abolished by tetrodotoxin. SAL's D1R-dependent effect on glutamatergic transmission is similar to that we observed previously with ethanol (Deng et al., 2009; Xiao et al., 2009); but SAL is much more potent than ethanol (the effective concentrations being $0.1 \mu \mathrm{M}$ for SAL vs. $40 \mathrm{mM}$ for ethanol). This is consistent with both in vivo and in vitro findings that the DA system is particularly sensitive to SAL (Hipolito et al., 2011; Rodd et al., 2008; Xie and Ye, 2012).

We showed that the ethanol-induced increase in the release of glutamate (EPSCs) in the VTA was eliminated when dopamine was depleted by pretreatment with reserpine (Deng et al., 2009; Xiao et al., 2009). Since SAL is the condensation product of dopamine and acetaldehyde, depletion of dopamine could prevent the formation of SAL. This could explain why ethanol failed to increase glutamatergic transmission when dopamine was depleted.

\section{SUMMARY}

Our in vitro findings in combination with in vivo experiments by other groups-reviewed here-identify cellular mechanisms underlying SAL's psychoactive effects on the mesolimbic dopamine system. SAL's stimulating action in the pVTA involves modulation of synaptic inputs and intrinsic properties of DA neurons (schematically depicted in Figure 1): (1) depolarizing DA neurons and increasing their firing rate; (2) activating MORs

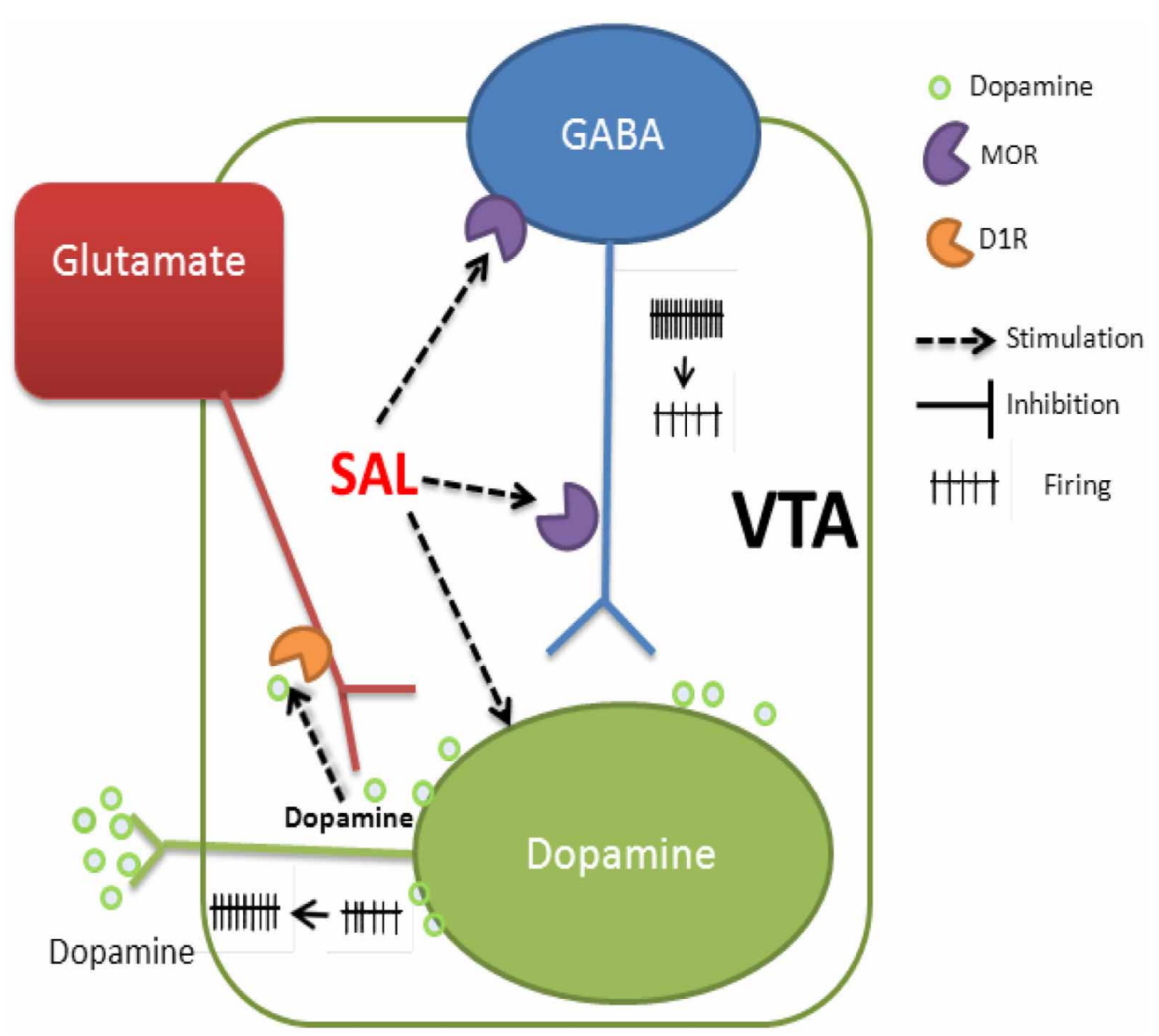

FIGURE 1 | Schematic representation of the mechanisms underlying SAL's excitation of putative DA neurons in rat Pvta. (1) Depolarizing the membrane and increasing the firing rate. (2) Activation of MORs on the
GABAergic neurons and/or their afferents reduces GABA release onto DA neurons. (3) Activation of D1Rs at the glutamatergic afferents increases glutamate release onto DA neurons. VTA, ventral tegmental area. 
on the GABAergic neurons, which inhibit GABAergic transmission to VTA DA neurons (resulting in disinhibition); (3) enhancing glutamatergic transmission to DA neurons by activating D1Rs situated on glutamatergic afferents. Thus, by acting on both presynaptic and postsynaptic targets on the DA neurons, SAL enhances the discharge of VTA DA neurons and so increases dopamine release in the downstream brain regions. Whatever its precise role-whether as detector of rewarding stimuli (Mirenowicz and Schultz, 1996) or modulating network activity in PFC (Durstewitz et al., 2000; González-Burgos et al.,

\section{REFERENCES}

Barrot, M., Sesack, S. R., Georges, F., Pistis, M., Hong, S., and Jhou, T. C. (2012). Braking dopamine systems: a new GABA master structure for mesolimbic and nigrostriatal functions. J. Neurosci. 32, 14094-14101.

Blum, K., Noble, E. P., Sheridan, P. J., Montgomery, A., Ritchie, T., Jagadeeswaran, P., et al. (1990). Allelic association of human dopamine D2 receptor gene in alcoholism. JAMA 263, 2055-2060.

Brazhnik, E., Shah, F., and Tepper, J. M. (2008). GABAergic afferents activate both GABAA and GABAB receptors in mouse substantia nigra dopaminergic neurons in vivo. J. Neurosci. 28, 10386-10398.

Brodie, M. S., Shefner, S. A., and Dunwiddie, T. V. (1990). Ethanol increases the firing rate of dopamine neurons of the rat ventral tegmental area in vitro. Brain Res. 508, 65-69.

Charara, A., Smith, Y., and Parent, A. (1996). Glutamatergic inputs from the pedunculopontine nucleus to midbrain dopaminergic neurons in primates: phaseolus vulgarisleucoagglutinin anterograde labeling combined with postembedding glutamate and GABA immunohistochemistry. J. Comp. Neurol. 364, 254-266.

Chieng, B., Azriel, Y., Mohammadi, S., and Christie, M. J. (2011). Distinct cellular properties of identified dopaminergic and GABAergic neurons in the mouse ventral tegmental area. J. Physiol. 589, 3775-3787.

Christoffersen, C. L., and Meltzer, L. T. (1995). Evidence for N-methylD-aspartate and AMPA subtypes of the glutamate receptor on substantia nigra dopamine neurons: possible preferential role for N-methylD-aspartate receptors. Neuroscience 67, 373-381.

Clements, J. R., Toth, D. D., Highfield, D. A., and Grant, S. J. (1991). Glutamate-like immunoreactivity is present within cholinergic neurons of the laterodorsal tegmental and pedunculopontine nuclei. $A d v$. Exp. Med. Biol. 295, 127-142.
Comoli, E., Coizet, V., Boyes, J., Bolam, J. P., Canteras, N. S., Quirk, R. H., et al. (2003). A direct projection from superior colliculus to substantia nigra for detecting salient visual events. Nat. Neurosci. 6, 974-980.

Dahchour, A., Hoffman, A., Deitrich, R., and de Witte, P. (2000). Effects of ethanol on extracellular amino acid levels in high-and low-alcohol sensitive rats: a microdialysis study. Alcohol Alcohol. 35, 548-553.

Deehan, G. A. Jr., Brodie, M. S., and Rodd, Z. A. (2013a). What is in that drink: the biological actions of ethanol, acetaldehyde, and salsolinol. Curr. Top. Behav. Neurosci. 13, 163-184.

Deehan, G. A. Jr., Engleman, E. A., Ding, Z. M., McBride, W. J., and Rodd, Z. A. (2013b). Microinjections of acetaldehyde or salsolinol into the posterior ventral tegmental area increase dopamine release in the nucleus accumbens shell. Alcohol. Clin. Exp. Res. 37, 722-729.

Deng, C., Li, K. Y., Zhou, C., and Ye, J. H. (2009). Ethanol enhances glutamate transmission by retrograde dopamine signaling in a postsynaptic neuron/synaptic bouton preparation from the ventral tegmental area. Neuropsychopharmacology 34, 1233-1244.

Deng, X. S., and Deitrich, R. A. (2008). Putative role of brain acetaldehyde in ethanol addiction. Curr. Drug Abuse Rev. 1, 3-8.

Di Chiara, G., and Imperato, A. (1988). Drugs abused by humans preferentially increase synaptic dopamine concentrations in the mesolimbic system of freely moving rats. Proc. Natl. Acad. Sci. U.S.A. 85, 5274-5278.

Ding, Z. M., Engleman, E. A., Rodd, Z. A., and McBride, W. J. (2012). Ethanol increases glutamate neurotransmission in the posterior ventral tegmental area of female wistar rats. Alcohol. Clin. Exp. Res. 36, 633-640.

Dobi, A., Margolis, E. B., Wang, H. L., Harvey, B. K., and Morales,

2002; Lapish et al., 2007) —it is clear that the mesocortical DA system is important in processes leading to addiction. Hence, the novel mechanisms proposed here may contribute to the rewarding properties of SAL observed in vivo. Understanding how SAL affects the activity of VTA dopamine neurons could have profound implications for the prevention and treatment of alcoholism.

\section{ACKNOWLEDGMENTS}

This work is made possible by the support of NIH AA016964.

M. (2010). Glutamatergic and nonglutamatergic neurons of the ventral tegmental area establish local synaptic contacts with dopaminergic and nondopaminergic neurons. J. Neurosci. 30, 218-229.

Dommett, E., Coizet, V., Blaha, C. D., Martindale, J., Lefebvre, V., Walton, N., et al. (2005). How visual stimuli activate dopaminergic neurons at short latency. Science 307, 1476-1479.

Duncan, C., and Deitrich, R. A. (1980). A critical evaluation of tetrahydroisoquinoline induced ethanol preference in rats. Pharmacol. Biochem. Behav. 13, 265-281.

Durstewitz, D., Seamans, J. K. and Sejnowski, T. J. (2000). Neurocomputational models of working memory. Nat. Neurosci. 3(Suppl.), 1184-1191.

Eckardt, M. J., File, S. E., Gessa, G. L., Grant, K. A., Guerri, C., Hoffman, P. L., et al. (1998). Effects of moderate alcohol consumption on the central nervous system. Alcohol. Clin. Exp. Res. 22, 998-1040.

El-Ghundi, M., George, S. R., Drago, J., Fletcher, P. J., Fan, T., Nguyen, T., et al. (1998). Disruption of dopamine D1 receptor gene expression attenuates alcohol-seeking behavior. Eur. J. Pharmacol. 353, 149-158.

Faraj, B. A., Camp, V. M., Davis, D. C., Lenton, J. D., and Kutner, M. (1989). Elevation of plasma salsolinol sulfate in chronic alcoholics as compared to nonalcoholics. Alcohol. Clin. Exp. Res. 13, 155-163.

Fertel, R. H., Greenwald, J. E., Schwarz, R., Wong, L., and Bianchine, J. (1980). Opiate receptor binding and analgesic effects of the tetrahydroisoquinolines salsolinol and tetrahydropapaveroline. Res. Commun. Chem. Pathol. Pharmacol. 27, 3-16.

Gallegos, R. A., Lee, R. S., Criado, J. R., Henriksen, S. J., and Steffensen, S. C. (1999). Adaptive responses of gamma-aminobutyric acid neurons in the ventral tegmental area to chronic ethanol. J. Pharmacol. Exp. Ther. 291, 1045-1053.

Geisler, S., Derst, C., Veh, R. W., and Zahm, D. S. (2007). Glutamatergic afferents of the ventral tegmental area in the rat. J. Neurosci. 27, 5730-5743.

Georges, F., and Aston-Jones, G. (2002). Activation of ventral tegmental area cells by the bed nucleus of the stria terminalis: a novel excitatory amino acid input to midbrain dopamine neurons. J. Neurosci. 22, 5173-5187.

Gonçalves, L., Sego, C., and Metzger, M. (2012). Differential projections from the lateral habenula to the rostromedial tegmental nucleus and ventral tegmental area in the rat. J. Comp. Neurol. 520, 1278-1300.

González-Burgos, G., Kröner, S., Krimer, L. S., Seamans, J. K., Urban, N. N., Henze, D. A., et al. (2002). Dopamine modulation of neuronal function in the monkey prefrontal cortex. Physiol. Behav. 77, 537-543.

Guan, Y., Xiao, C., Krnjevic, K., Xie, G., Zuo, W., and Ye, J. H. (2012). GABAergic actions mediate opposite ethanol effects on dopaminergic neurons in the anterior and posterior ventral tegmental area. J. Pharmacol. Exp. Ther. 341, 33-42.

Haber, H., Dumaual, N., Bare, D. J., Melzig, M. F., McBride, W. F., Lumeng, L., et al. (1999). The quantitative determination of $\mathrm{R}$ - and S-salsolinol in the striatum and adrenal gland of rats selectively bred for disparate alcohol drinking. Addict. Biol. 4, 181-189.

Haber, H., Winkler, A., Putscher, I., Henklein, P., Baeger, I., Georgi, M., et al. (1996). Plasma and urine salsolinol in humans: effect of acute ethanol intake on the enantiomeric composition of salsolinol. Alcohol. Clin. Exp. Res. 20, 87-92.

Hipolito, L., Marti-Prats, L., SanchezCatalan, M. J., Polache, A., and Granero, L. (2011). Induction of conditioned place preference and dopamine release by salsolinol in posterior VTA of rats: involvement 
of mu-opioid receptors. Neurochem. Int. 59, 559-562.

Hipolito, L., Sanchez-Catalan, M. J., Granero, L., and Polache, A. (2009). Local salsolinol modulates dopamine extracellular levels from rat nucleus accumbens: shell/core differences. Neurochem. Int. 55, 187-192.

Hipolito, L., Sanchez-Catalan, M. J., Marti-Prats, L., Granero, L., and Polache, A. (2012). Revisiting the controversial role of salsolinol in the neurobiological effects of ethanol: old and new vistas. Neurosci. Biobehav. Rev. 36, 362-378.

Hipolito, L., Sanchez-Catalan, M. J., Zornoza, T., Polache, A., and Granero, L. (2010). Locomotor stimulant effects of acute and repeated intrategmental injections of salsolinol in rats: role of mu-opioid receptors. Psychopharmacology (Berl.) 209, $1-11$.

Hjelmstad, G. O., Xia, Y., Margolis, E. B., and Fields, H. L. (2013). Opioid modulation of ventral pallidal afferents to ventral tegmental area neurons. J. Neurosci. 33, 6454-6459.

Ikemoto, S., Kohl, R. R., and McBride, W. J. (1997). GABA(A) receptor blockade in the anterior ventral tegmental area increases extracellular levels of dopamine in the nucleus accumbens of rats. J. Neurochem. 69 , 137-143.

Jalabert, M., Bourdy, R., Courtin, J., Veinante, P., Manzoni, O. J., Barrot, M., et al. (2011). Neuronal circuits underlying acute morphine action on dopamine neurons. Proc. Natl. Acad. Sci. U.S.A. 108, 16446-16450.

Jhou, T. C., Fields, H. L., Baxter, M. G., Saper, C. B., and Holland, P. C. (2009). The rostromedial tegmental nucleus (RMTg), a GABAergic afferent to midbrain dopamine neurons, encodes aversive stimuli and inhibits motor responses. Neuron 61, 786-800.

Johnson, S. W., and North, R. A. (1992a). Opioids excite dopamine neurons by hyperpolarization of local interneurons. J. Neurosci. 12, 483-488.

Johnson, S. W., and North, R. A. (1992b). Two types of neurone in the rat ventral tegmental area and their synaptic inputs. J. Physiol. 450, 455-468.

Kalivas, P. W. (1993). Neurotransmitter regulation of dopamine neurons in the ventral tegmental area. Brain Res. Brain Res. Rev. 18, 75-113.

Kalivas, P. W., Churchill, L., and Klitenick, M. A. (1993). GABA and enkephalin projection from the nucleus accumbens and ventral pallidum to the ventral tegmental area. Neuroscience 57, 1047-1060.

Kalivas, P. W., and Duffy, P. (1995). D1 receptors modulate glutamate transmission in the ventral tegmental area. J. Neurosci. 15, 5379-5388.

Karahanian, E., Quintanilla, M. E., Tampier, L., Rivera-Meza, M., Bustamante, D., Gonzalez-Lira, V., et al. (2011). Ethanol as a prodrug: brain metabolism of ethanol mediates its reinforcing effects. Alcohol. Clin. Exp. Res. 35, 606-612.

Krystal, J. H., D'Souza, D. C., Mathalon, D., Perry, E., Belger, A., and Hoffman, R. (2003). NMDA receptor antagonist effects, cortical glutamatergic function, and schizophrenia: toward a paradigm shift in medication development. Psychopharmacology (Berl.) 169, 215-233.

Lacey, M. G., Mercuri, N. B., and North, R. A. (1989). Two cell types in rat substantia nigra zona compacta distinguished by membrane properties and the actions of dopamine and opioids. J. Neurosci. 9, 1233-1241.

Lapish, C. C., Kroener, S., Durstewitz, D., Lavin, A., and Seamans, J. K. (2007). The ability of the mesocortical dopamine system to operate in distinct temporal modes. Psychopharmacology (Berl.) 191, 609-625.

Latimer, L. G., Duffy, P., and Kalivas, P. W. (1987). Mu opioid receptor involvement in enkephalin activation of dopamine neurons in the ventral tegmental area. J. Pharmacol. Exp. Ther. 241, 328-337.

Laviolette, S. R., and van der Kooy, D. (2001). GABA(A) receptors in the ventral tegmental area control bidirectional reward signalling between dopaminergic and nondopaminergic neural motivational systems. Eur. J. Neurosci. 13, 1009-1015.

Lavoie, B., and Parent, A. (1994). Pedunculopontine nucleus in the squirrel monkey: distribution of cholinergic and monoaminergic neurons in the mesopontine tegmentum with evidence for the presence of glutamate in cholinergic neurons. J. Comp. Neurol. 344, 190-209.

Leone, P., Pocock, D., and Wise, R. A. (1991). Morphine-dopamine interaction: ventral tegmental morphine increases nucleus accumbens dopamine release. Pharmacol. Biochem. Behav. 39, 469-472.

Liu, X., and Weiss, F. (2002). Additive effect of stress and drug cues on reinstatement of ethanol seeking: exacerbation by history of dependence and role of concurrent activation of corticotropin-releasing factor and opioid mechanisms. J. Neurosci. 22, 7856-7861.

Lu, X. Y., Churchill, L., and Kalivas, P. W. (1997). Expression of D1 receptor mRNA in projections from the forebrain to the ventral tegmental area. Synapse 25, 205-214.

Lucchi, L., Bosio, A., Spano, P. F., and Trabucchi, M. (1982). Action of ethanol and salsolinol on opiate receptor function. Brain Res. 232, 506-510.

Lüscher, C., and Malenka, R. C. (2011). Drug-evoked synaptic plasticity in addiction: from molecular changes to circuit remodeling. Neuron 69 , 650-663.

Mansour, A., Fox, C. A., Akil, H., and Watson, S. J. (1995). Opioidreceptor mRNA expression in the rat CNS: anatomical and functional implications. Trends Neurosci. 18, 22-29.

Mansour, A., Meador-Woodruff, J. H., Zhou, Q., Civelli, O., Akil, H., and Watson, S. J. (1992). A comparison of $\mathrm{D} 1$ receptor binding and mRNA in rat brain using receptor autoradiographic and in situ hybridization techniques. Neuroscience 46 , 959-971.

Matsubara, K., Fukushima, S., and Fukui, Y. (1987). A systematic regional study of brain salsolinol levels during and immediately following chronic ethanol ingestion in rats. Brain Res. 413, 336-343.

Matsui, A., and Williams, J. T. (2011). Opioid-sensitive GABA inputs from rostromedial tegmental nucleus synapse onto midbrain dopamine neurons. J. Neurosci. 31, 17729-17735.

Matsuzawa, S., Suzuki, T., and Misawa, M. (2000). Involvement of muopioid receptor in the salsolinolassociated place preference in rats exposed to conditioned fear stress. Alcohol. Clin. Exp. Res. 24, 366-372.

Matthews, R. T., and German, D. C. (1984). Electrophysiological evidence for excitation of rat ventral tegmental area dopamine neurons by morphine. Neuroscience 11 , 617-625.

Melis, M., Diana, M., Enrico, P., Marinelli, M., and Brodie, M. S. (2009). Ethanol and acetaldehyde action on central dopamine systems: mechanisms, modulation, and relationship to stress. Alcohol $43,531-539$.

Mirenowicz, J., and Schultz, W. (1996). Preferential activation of midbrain dopamine neurons by appetitive rather than aversive stimuli. Nature $379,449-451$.

Morikawa, H., and Morrisett, R. A. (2010). Ethanol action on dopaminergic neurons in the ventral tegmental area: interaction with intrinsic ion channels and neurotransmitter inputs. Int. Rev. Neurobiol. 91, 235-288.

Myers, R. D., McCaleb, M. L., and Ruwe, W. D. (1982). Alcohol drinking induced in the monkey by tetrahydropapaveroline (THP) infused into the cerebral ventricle. Pharmacol. Biochem. Behav. 16, 995-1000.

Myers, W. D., Mackenzie, L., Ng, K. T., Singer, G., Smythe, G. A., and Duncan, M. W. (1985). Salsolinol and dopamine in rat medial basal hypothalamus after chronic ethanol exposure. Life Sci. 36, 309-314.

Nair-Roberts, R. G., Chatelain-Badie, S. D., Benson, E., White-Cooper, H., Bolam, J. P., and Ungless, M. A. (2008). Stereological estimates of dopaminergic, GABAergic and glutamatergic neurons in the ventral tegmental area, substantia nigra and retrorubral field in the rat. Neuroscience 152, 1024-1031.

Naoi, M., Maruyama, W., Nakao, N., Ibi, T., Sahashi, K., and Benedetti, M. S. (1998). (R)salsolinol Nmethyltransferase activity increases in parkinsonian lymphocytes. Ann. Neurol. 43, 212-216.

Oades, R. D., and Halliday, G. M. (1987). Ventral tegmental (A10) system: neurobiology. 1. Anatomy and connectivity. Brain Res. 434, $117-165$.

Omelchenko, N., Bell, R., and Sesack, S. R. (2009). Lateral habenula projections to dopamine and GABA neurons in the rat ventral tegmental area. Eur. J. Neurosci. 30, 1239-1250.

Overton, P. G., and Clark, D. (1997). Burst firing in midbrain dopaminergic neurons. Brain Res. Brain Res. Rev. 25, 312-334.

Rehm, J., Mathers, C., Popova, S., Thavorncharoensap, M., Teerawattananon, Y., and Patra, J. (2009). Global burden of disease and injury and economic cost attributable to alcohol use and alcohol-use disorders. Lancet. 373, 2223-2233.

Roberto, M., Schweitzer, P., Madamba, S. G., Stouffer, D. G., Parsons, L. H., and Siggins, G. R. (2004). Acute and chronic ethanol alter glutamatergic transmission in rat central amygdala: an in vitro and in vivo analysis. J. Neurosci. 24, 1594-1603.

Rodd, Z. A., Bell, R. L., Zhang, Y., Goldstein, A., Zaffaroni, A., McBride, W. J., et al. (2003) 
Salsolinol produces reinforcing effects in the nucleus accumbens shell of alcohol-preferring (P) rats. Alcohol. Clin. Exp. Res. 27, 440-449.

Rodd, Z. A., Oster, S. M., Ding, Z. M., Toalston, J. E., Deehan, G., Bell, R. L., et al. (2008). The reinforcing properties of salsolinol in the ventral tegmental area: evidence for regional heterogeneity and the involvement of serotonin and dopamine. Alcohol. Clin. Exp. Res. 32, 230-239.

Rojkovicova, T., Mechref, Y., Starkey, J. A., Wu, G., Bell, R. L., McBride, W. J., et al. (2008). Quantitative chiral analysis of salsolinol in different brain regions of rats genetically predisposed to alcoholism. J. Chromatogr. B Analyt. Technol. Biomed. Life Sci. 863, 206-214.

Rommelspacher, H., Sllstrom Baum, S., Dufeu, P., and Schmidt, L. G. (1995). Determination of (R)- and (S)-salsolinol sulfate and dopamine sulfate levels in plasma of nonalcoholics and alcoholics. Alcohol 12, 309-315.

Selim, M., and Bradberry, C. W. (1996). Effect of ethanol on extracellular 5HT and glutamate in the nucleus accumbens and prefrontal cortex: comparison between the Lewis and Fischer 344 rat strains. Brain Res. 716, 157-164.

Sesack, S. R., Carr, D. B., Omelchenko, N., and Pinto, A. (2003). Anatomical substrates for glutamate-dopamine interactions: evidence for specificity of connections and extrasynaptic actions. Ann. N.Y. Acad. Sci. 1003, 36-52.

Siggins, G. R., Roberto, M., and Nie, Z. (2005). The tipsy terminal: presynaptic effects of ethanol. Pharmacol. Ther. 107, 80-98.
Sjöquist, B., Eriksson, A., and Winblad, B. (1982a). Brain salsolinol levels in alcoholism. Lancet 1, 675-676.

Sjöquist, B., Liljequist, S., and Engel, J. (1982b). Increased salsolinol levels in rat striatum and limbic forebrain following chronic ethanol treatment. J. Neurochem. 39, 259-262.

Smith, B. R., Robidoux, J., and Amit, Z. (1992). GABAergic involvement in the acquisition of voluntary ethanol intake in laboratory rats. Alcohol Alcohol. 27, 227-231.

Spanagel, R., Bartsch, D., Brors, B. Dahmen, N., Deussing, J., Eils, R., et al. (2010). An integrated genome research network for studying the genetics of alcohol addiction. Addict. Biol. 15, 369-379.

Spanagel, R., Herz, A., and Shippenberg, T. S. (1992). Opposing tonically active endogenous opioid systems modulate the mesolimbic dopaminergic pathway. Proc. Natl. Acad. Sci. U.S.A. 89 2046-2050.

Starkey, J. A., Mechref, Y., Muzikar, J., McBride, W. J., and Novotny, M. V. (2006). Determination of salsolinol and related catecholamines through on-line preconcentration and liquid chromatography/atmospheric pressure photoionization mass spectrometry. Anal. Chem. 78, 3342-3347.

Tan, K. R., Yvon, C., Turiault, M., Mirzabekov, J. J., Doehner, J., Labouèbe, G., et al. (2012). GABA neurons of the VTA drive conditioned place aversion. Neuron 73, 1173-1183.

Theile, J. W., Morikawa, H., Gonzales, R. A., and Morrisett, R. A. (2011) GABAergic transmission modulates ethanol excitation of ventral tegmental area dopamine neurons. Neuroscience 172, 94-103.
Threlfell, S., and Cragg, S. J. (2007). "Chapter 8, using fast-scan cyclic voltammetry to investigate somatodendritic dopamine release," in Electrochemical Methods for Neuroscience, eds A. C. Michael and L. M. Borland (Boca Raton, FL: CRC Press).

Volkow, N. D., Fowler, J. S., Wang, G. J., Swanson, J. M., and Telang, F. (2007). Dopamine in drug abuse and addiction: results of imaging studies and treatment implications. Arch. Neurol. 64, 1575-1579.

Xiao, C., Shao, X. M., Olive, M. F. Griffin, W. C. 3rd, Li, K. Y., et al. (2009). Ethanol facilitates glutamatergic transmission to dopamine neurons in the ventral tegmental area. Neuropsychopharmacology 34, 307-318.

Xiao, C., and Ye, J. H. (2008). Ethanodually modulates GABAergic synaptic transmission onto dopaminergic neurons in ventral tegmental area: role of mu-opioid receptors. Neuroscience 153 , 240-248.

Xiao, C., Zhang, J., Krnjevic, K., and Ye, J. H. (2007). Effects of ethanol on midbrain neurons: role of opioid receptors. Alcohol. Clin. Exp. Res. 31 , 1106-1113.

Xie, G., and Ye, J. H. (2012). Salsolinol facilitates glutamatergic transmission to dopamine neurons in the posterior ventral tegmental area of rats. PLoS ONE 7:e36716. doi: 10.1371/journal.pone.0036716

Xie, G., Hipólito, L., Zuo, W., Polache, A., Granero, L., Krnjevic, K. et al. (2012). Salsolinol stimulates dopamine neurons in slices of posterior ventral tegmental area indirectly by activating $\mu$-opioid receptors. J. Pharmacol. Exp. Ther. 341, 43-50.
Yung, W. H., Hausser, M. A., and Jack, J. J. (1991). Electrophysiology of dopaminergic and nondopaminergic neurones of the guinea-pig substantia nigra pars compacta in vitro. J. Physiol. 436, 643-667.

Zhang, X. F., Hu, X. T., White, F. J., and Wolf, M. E. (1997). Increased responsiveness of ventral tegmental area dopamine neurons to glutamate after repeated administration of cocaine or amphetamine is transient and selectively involves AMPA receptors. J. Pharmacol. Exp. Ther. 281, 699-706.

Zhu, W., Bie, B., and Pan, Z. Z. (2007). Involvement of non-NMDA glutamate receptors in central amygdala in synaptic actions of ethanol and ethanol-induced reward behavior. J. Neurosci. 27, 289-298.

Conflict of Interest Statement: The authors declare that the research was conducted in the absence of any commercial or financial relationships that could be construed as a potential conflict of interest.

Received: 28 February 2013; accepted: 07 May 2013; published online: 24 May 2013.

Citation: Xie G, Krnjević $K$ and Ye $\mathrm{I}-\mathrm{H}$ (2013) Salsolinol modulation of dopamine neurons. Front. Behav. Neurosci. 7:52. doi: 10.3389/fnbeh. 2013.00052

Copyright (c) 2013 Xie, Krnjević and $Y$. This is an open-access article distributed under the terms of the Creative Commons Attribution License, which permits use, distribution and reproduction in other forums, provided the original authors and source are credited and subject to any copyright notices concerning any third-party graphics etc. 